\title{
Novelística de Manlio Argueta
}

"Sin lugar a dudas, Manlio es un hombre que camina con su tiempo a tono con las palabras y los hechos", recuerdo haber oído exclamar al poeta Roberto Armijo, una de esas noches en las que discutíamos sobre la literatura de nuestro país en su casa parisina de Montmartre. $\mathrm{Y}$ en efecto, tal como lo ejemplarizó Rimbaud -el Príncipe de los Malditos-, Manlio ha conjugado como el que más, vida y obra, literatura y praxis, hechos y palabras. La unión de contrarios del Tao - la sabiduría china que explica la vida como una serie de mutaciones y afrentas- se encuentra resumida en este narrador centroamericano quien es con justeza el más universal de los escritores salvadoreños.

Su vida personal es el reverso concurrente de una novelística fundadora creada en torno a la tragedia social de su país, El Salvador, tierra de conflictos políticos y hasta hace pocos años envuelta en una sangrienta guerra civil.

Protagonista de primera línea de la "izquierda heroica" que surgió en los años cincuenta entre el calor de las transformaciones socio-económicas y el nacimiento de la industria salvadoreña del seno de la oligarquía cafetalera, la generación de Manlio Argueta tomó como bandera de lucha la denuncia social y la militancia política en el más clásico estilo revolucionario.

De aquel "Círculo Cultural Universitario", fundado en 1956 que reunió a la vanguardia literaria del país, sobreviven pocos miembros, pasada ya la hoja acerada del balance final. Roque Dalton y Roberto Armijo, el primero el más alto poeta que ha dado el país, y el segundo, un ensayista de calibre mayor en el ámbito latinoamericano, fueron los compañeros de viajes y de letras de Manlio en dicha empresa, así como Alfonso Quijada Urías, que a pesar de haber llegado años más tarde a este círculo, se ubica generacionalmente entre los mismos.

La llamada "Generación Comprometida" practicó lo militancia política con una obediencia casi ciega y su ortodoxia —explicable por el marco internacional de la guerra fría y por los ecos del triunfo de la revolución cubana- llevó a sus escritores a producir una literatura que rondaba el panfleto. Sólo la genialidad y el talento artístico salvó del naufragio "contenidista" a los escritores arriba mencionados.

Pero no sólo la literatura, hechos como su incorporación al Ejército Rojo de la antigua Unión Soviética, donde hizo su "platada" militar en los años sesenta, así como su experiencia cubana, dejan entrever en Manlio Argueta al escritor visionario que asume con la praxis política su compromiso literario. Compromiso al que se encargó de darle el acabado cualitativo cuando, obligado por las circunstancias, rompió con la izquierda ortodoxa de la vieja guardia y se volvió uno de los hombres claves de la nueva izquierda salvadoreña. Más de treinta estadías en la cárcel y seis exilios, el último de ellos por espacio de veinte años en Costa Rica, así como la per- 
secución y las amenazas de muerte a la orden del día, dan testimonio de una vida legendaria, cuyas rutas y escalas se confunden entre Amsterdam, Moscú, Bonn, Tiflis, París, Washington, La Habana, Leningrado, México o San Miguel, San Salvador, San José.

A partir de 1970, fecha cuando es publicada su primera novela, El valle de las hamacas, hasta 1994 con su recién aparecida Milagro de la paz, la narrativa de Manlio describe una continuidad cualitativa en espiral ascendente que tiene en la continuidad político-social salvadoreña su mejor referente.

Su más famosa novela Un día en la vida ha sido traducida a más de diecisiete idiomas, elogiada por los más prestigiosos rotativos del mundo como Newsweek. The New York Times o Le Monde Diplomatique y logrado varias reediciones en numerosos países. Recuerdo, a manera de ilustración, una noche literaria en la ciudad alemana de Hannover, donde Manlio hacía una lectura de esta novela y donde, para nuestra sorpresa, se presentó un joven poeta iraní con la segunda edición en persa de Un día en la vida, que el mismo Manlio desconocía.

Gabriel García Márquez fue uno de los jurados que más influyó para que en 1976 se concediera el premio Casa de Las Américas por su novela Caperucita en la zona roja, para muchos críticos y estudiosos, lo mejor de su narrativa. Su producción también abarca Cuscatlán, donde bate la mar del sur, traducida a varios idiomas, publicada en Estados Unidos por la prestigiosa Random House y que próximamente será editada en alemán.

Su prosa sobresale no sólo como el producto de un trabajo bibliotecario, sino como resultado de una vida intensa y múltiple. Manlio pertenece a esa categoría de novelistas que reúne en su obra las tres condiciones fundamentales de todo narrador: cultura bibliotecaria, vivencias personales y fidelidad a una tradición narrativa que, en el caso salvadoreño, fue iniciada por don Francisco Gavidia y su prosa magistral. La suya es una vida de luchas literarias y políticas que se ha abierto a nivel mundial como a pulso limpio, con la calidad y la exigencia ética que toda obra de arte ver-

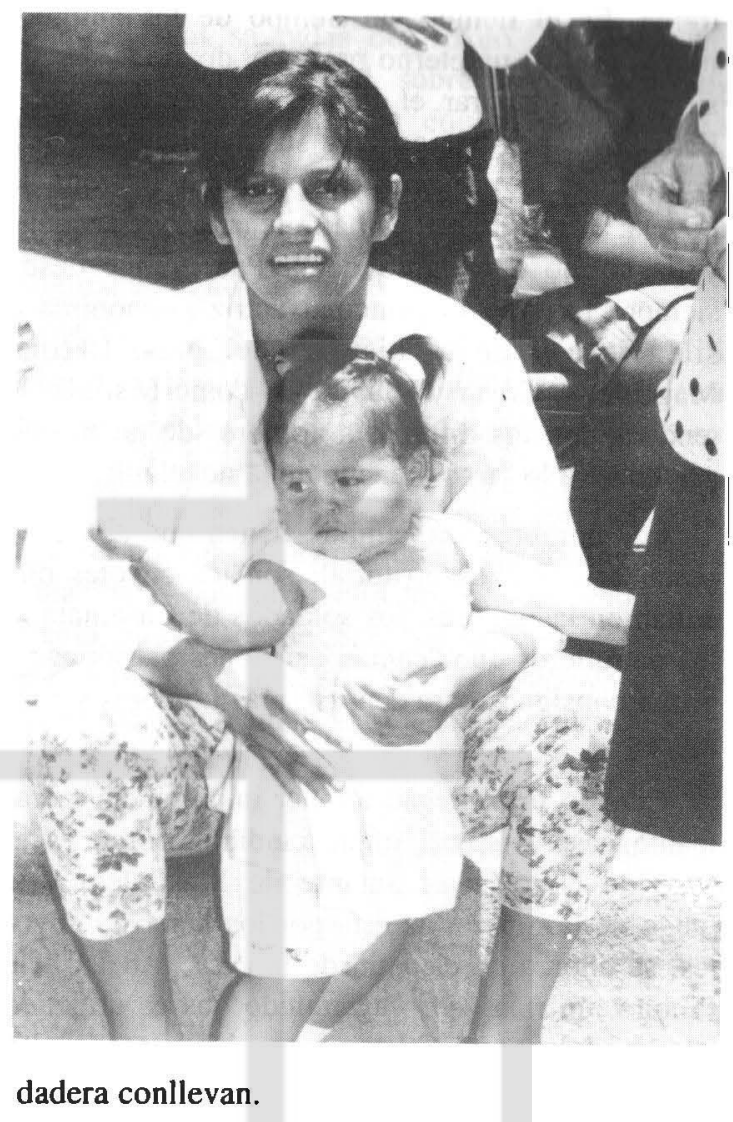

Milagro de la paz es la última novela de este autor casi sesentón (1936), y ha sido publicada en EL Salvador por la casa Istmo Editores que dirige el editor Jaime Barba. La edición en papel bond y con una portada a varios colores, habla de la seriedad con la que las editoriales centroamericanas abordan su labor, que en este sentido nada tienen que envidiar a otras editoriales del mundo.

Milagro de la paz es una obra escrita al margen del tiempo, con un excelente manejo técnico de diferentes planos espaciales, que, sin embargo, no escapan al centro gravitacional de la misma, un antiguo barrio colonial del que ha tomado su nombre, "fundado el ocho de mayo de 1530, a la orilla del río Texcuco, pequeño afluente del río Siramá".

Precisando, se trata de una historia con un tiempo circular que tiene como principales protagonistas a tres mujeres - la abuela, la hija y la nieta- que dan el toque vivencial de toda la 
trama. Es el tiempo sin tiempo de los antiguos mayas brujos: un eterno presente, donde el pasado sirve para elaborar el futuro a través del ahora. Estos tres personajes con sus particularidades, conforman la protagonista principal de toda la novela: la mujer, esa ceiba milenaria que sostiene y da cobijo a Milagro de la Paz, y que desde siempre ha sido la principal actriz -anónima y silenciosa- de la historia del país. Latina, Magdalena, Crista y Lluvia, así como Matilde, la tendera, son los diferentes nombres de un mismo personaje a lo largo y ancho de la novela.

Los hombres, en cambio, tienen una actividad secundaria y extraterritorial: son los coyotes que aúllan en las afueras, los soldados de Casamata, o los patrulleros que "cantan canciones patrióticas y gritan consignas para sentirse más hombres y más felices".

Cuando más, llegan a tener importancia meramente casual y casi imprescindible, como es el caso de Nicolás, el amante de Magdalena que luego de la muerte de ésta por los hombres coyotes, se ahorca en el patio de la casa, o del Chele Pintura, un marinero vagamundo que es utilizado por la adolescente Crista como objeto procreador en su más clásica acepción.

La novela está llena de simbolismos, que le dan una carga poética muy intensa a sus capítulos. Empecemos, sin embargo, señalando que las mariposas del deseo que sobrevuelan el vientre de Magdalena y Crista, así como las mariposas del prendedor capilar en la cabeza de Lluvia, no obstante recuerden al Mauricio Babilonia de Cien años de soledad, logran darle un verdadera atmósfera mítica al relato. Enumérese sino la palabra indígena para mariposa - papalotl, que en nahuatl y pipil significa "mariposa de obsidiana", y que es debidamente camuflajeada, la misma Virgen Morena o Virgen de Guadalupe adorada en Méxicoasí como su carácter simbólico de la libertad, pero también su carga fúnebre, ya que quien toca una mariposa y se pasa los dedos por los ojos queda ciego de por vida, según la creencia popular.

El Chaparrastique es otro símbolo masculino importante de la novela, ya que siempre está bombardeando a sus habitantes, rugiendo, en guerra constante, como sus hombres. Sin embargo, de sus entrañas sale Lluvia del Volcán, quizás el resumen más poético de toda la novela. Agua y fuego, aparentemente en contradicción, son la simbiosis de elementos que conforman a la niña protagonista. Las mariposas en su cabeza, simbolizan la luz al final del túnel, ya que después de bajar el volcán - ¿los hombres, la guerra?- encuentra por fin ella — ¿la patria?- el Milagro de la Paz.

Como dije anteriormente, en los tiempos circulares de la novela -elementos femeninos por excelencia con su clara alusión lunar-, la única posibilidad de plasticidad lo constituyen los bombardeos y rugidos del volcán, la fecundidad de las mujeres y las rosas rojas, que están en permanente floración, desflorando el estatismo espacial del barrio.

El protagonismo de Las estrellas en el pozo que también juegan un importante papel referencial en la novela, es un homenaje a la Madre Claudia Lars, la autora de este libro que es un clásico y una cima de la poesía hispanoamericana de todos los tiempos.

El doctor en hierbas, Febles, con sus recetas para curar enfermedades con aguas azules, rememora bastante al mismo procedimiento usado por el dictador-teósofo salvadoreño Hernández Martínez, el "tirano de las aguas azules".

El final es amplio aunque incierto -reflejo fiel de ese aire enviciado que han traído los nuevos tiempos de la posguerra-y dentro de toda la estructura de la novela, da lo mismo leerla al principio, en medio o al final, ya que su carácter circular le da una flexibilidad tal que es una historia siempre abierta a todas las posibilidades y desenlaces. Sin embargo, el círculo mágico de las tres mujeres no se rompe nunca, es un círculo de fuego o de tiza imposible de destruir, que asimila toda la tragedia del país: dentro de éste, se ingresa a un mundo fantástico e inexplicable, que es narrado con una maestría inédita hasta el momento en la literatura salvadoreña y que me hace pensar inmediatamente en Comala de Pedro Páramo y sus calles llenas de susurros y fantasmas: en Milagro de la Paz están presentes todos los 
muertos, todos sus susurros y sueños cobran vida en cada esquina o en lugares místicos que para'dójicamente están representados por el escusado -el lugar escatológico (del más allá y del más afuera) por excelencia - y por el pozo, que dentro de la novela es el reverso del cielo donde se reflejan las estrellas.

Un elemento misterioso de toda obra de arte trascendental se encuentra presente en esta novela, y es ese paso mágico de la realidad cotidiana de Milagro de la Paz al universo de los muertos y los sueños, en cuya profundidad (mundo invisible e impenetrable), los desaparecidos y los asesinados vuelven a cobrar vida con sus diferentes pesadillas e ilusiones. Como telón de acero a su marco de referencia, la novela tiene esa enorme carga de violencia que constituye la guerra, el estado de sitio, la permanente violación de los derechos humanos por los coyotes y los militares.

Hay momentos en que se ingresa a otras áreas, a unas zonas sagradas del relato que son coto vedado a la cotidianidad, sobre todo en los monólogos de Juan Bautista con la desaparecida Magdalena en el escusado, o el encuentro con las fronteras del infinito y sus estrellas en el pozo del patio familiar. No por mera casualidad el título original de la novela era "El escusado".

En cuanto al trabajo formal y al lenguaje, el relato está bien acabado y denota la mano maestra de un narrador de gran calidad y dueño de su oficio, que para suerte de la literatura salvadoreña, ha decidido desde hace dos años ser fiel a su carácter novelesco, aceptando el reto de una nueva mutación -comenzar otra vez con un "borrón y cuenta nueva" desde San Salvador- y de una bellísima novela que se inscribe desde ya en los anales de la mejor literatura salvadoreña de este agonizable milenio.

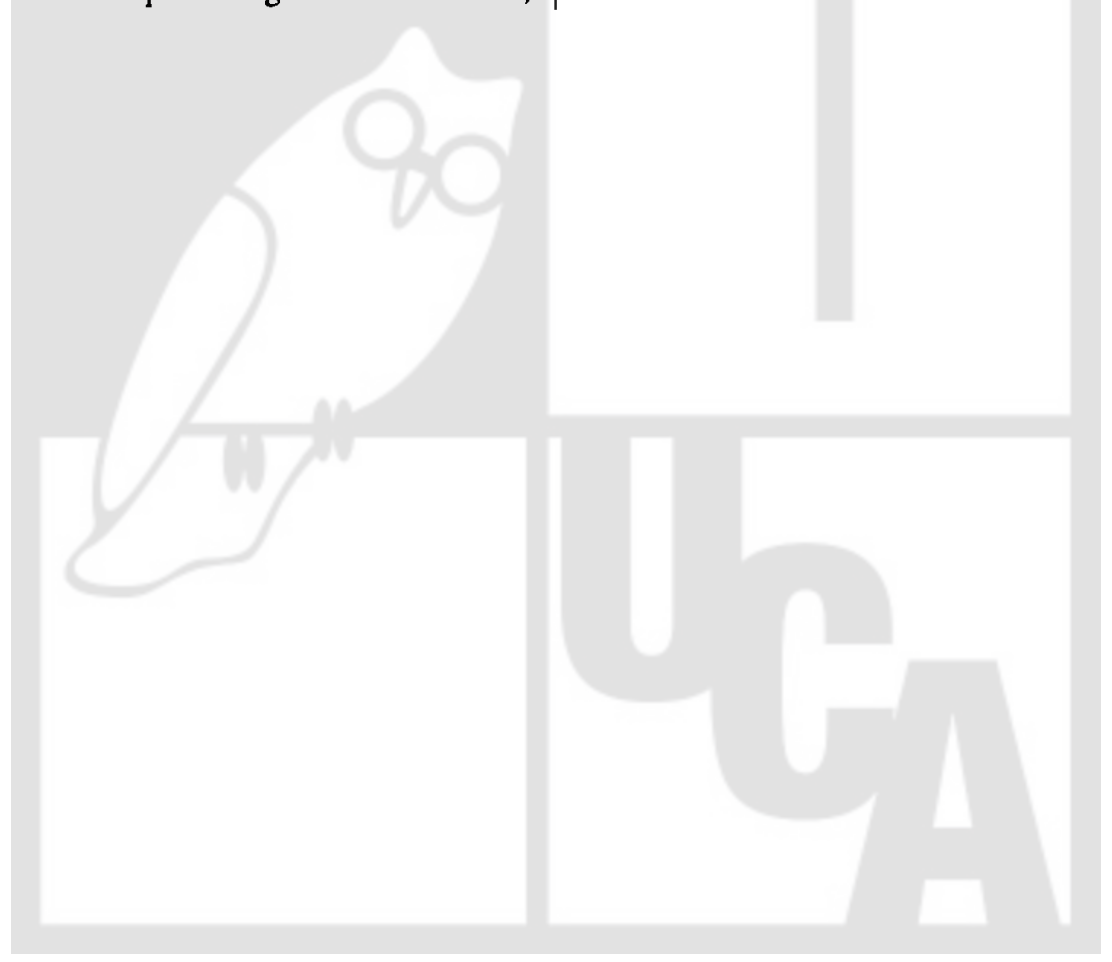

